\title{
La cultura de la conectividad: una historia crítica de las redes sociales
}

Elkin Rubiano-Pinilla1

DOI: $10.5294 /$ pacla.2017.20.2.12

Van Dijck, J. (2016). La cultura de la conectividad: una historia crítica de las redes sociales. Buenos Aires: Siglo XXI.

\section{Lo conectivo y lo social en las redes sociales}

En el libro La cultura de la conectividad: una historia crítica de las redes sociales, José van Dijck realiza una investigación sobre lo que denomina el ecosistema de los medios conectivos. La autora tipifica las plataformas en cuatro categorías: 1 . sitios de red social, 2 . sitios dedicados al contenido generado por los usuarios, 3. sitios de mercadotecnia y comercialización y 4. sitios de juego y entretenimiento (p. 24). La investigación se concentró, principalmente, en las dos primeras categorías mediante el análisis de cinco plataformas: Facebook, Twitter, Flickr, YouTube y Wikipedia. Teóricamente, la autora construye un modelo de análisis de carácter sistémico: un ecosistema de los medios conectivos conformado por microsistemas (plataformas). Cada microsistema se estructura en dos niveles y seis elementos, como se ilustra en la siguiente tabla.

\begin{tabular}{|l|l|}
\hline \multicolumn{2}{|c|}{ Microsistema } \\
\hline \multicolumn{1}{|c|}{ Nivel tecnocultural } & \multicolumn{1}{c|}{ Nivel socioeconómico } \\
\hline 1. Tecnología & 3. Gobierno \\
\hline 2. Usuario y hábito & 4. Negocio \\
\hline 5. Contenido & 6. Propiedad \\
\hline
\end{tabular}

Como lo indica el subtítulo del libro, la postura de Van Dijck es crítica con respecto a las redes sociales. Por ejemplo, pone en duda los supuestos sobre la interacción social, pues más que medios sociales las plataformas

1 Universidad Jorge Tadeo Lozano. Colombia. elkin.rubiano@utadeo.edu.co 
son medios conectivos: "La denominación 'social' se ha convertido en un paraguas que oculta más que lo que revela” (p. 280), de modo que uno de los propósitos de la autora es revelar aquello que no resulta visible en acciones corrientes como "compartir", "seguir" o dar "me gusta". En las relaciones que se construyen entre los humanos y las máquinas, es indispensable comprender las lógicas de los algoritmos, los metadatos y los bots, pues lo social en las redes se construye tanto por la conexión humana como por la conectividad automática (p. 30). Cuando se relacionan usos, contenido y negocio, por ejemplo, se revela que "compartir" no solo es una operación de conexión realizada por los usuarios, sino que también significa que los usuarios comparten sus datos con terceros. El diseño de los algoritmos permite construir tenencias mediante relaciones como la siguiente: ¿quién comparte qué, con quién, dónde y con qué frecuencia? Los bots, máquinas inteligentes, realizan una labor de "minería" en la que se extraen datos (estados de ánimo, opiniones y gustos) para rastrear tendencias en tiempo real y dirigir la publicidad de manera personalizada: avisos "custumizados", productos recomendados por amigos o personas con gran cantidad de seguidores (p. 136).

Esto último configura una de las lógicas centrales de las redes sociales: la popularidad, es decir, la concentración de la atención en un porcentaje reducido de los usuarios. Esto último resulta problemático en Twitter, que nació con la promesa de ser un ágora global o en YouTube, que prometió ser el reino de la creación para cualquiera (los youtubers). Los datos echan por tierra las celebraciones de la producción activa de los usuarios y consumidores, popularizada con expresiones como "produsuarios" o "prosumidores", pues, por ejemplo, "un $4 \%$ de los usuarios de YouTube brinda casi tres cuartas partes del contenido del sitio" (p. 191). No solo hay pocas evidencias sobre el usuario como proveedor de contenido, sino que, además, este usuario es claramente dirigido hacia contenidos definidos por cada plataforma.

A pesar de los regímenes de propiedad y formas de gobierno verticales, existe una plataforma no comercial que se encuentra entre las diez más importantes de internet: Wikipedia, cuya forma de gobierno, siguiendo una idea de Toffler, podría caracterizarse como una "adhocracia": "una 
multiplicidad de equipos multidisciplinarios ad hoc que conforman alianzas temporarias para crear y mantener contenido según tareas bien definidas" (p. 240). Lo anterior no quiere decir que Van Dijck celebre incondicionalmente esta plataforma, pues su contenido elimina el disenso, cuestión problemática para muchos de los colaboradores activos que consideran que las políticas editoriales de Wikipedia no permiten la diversidad de pensamiento. Ahora bien, si los medios conectivos conforman un ecosistema, Wikipedia, independiente de su carácter no comercial, no es ajena a las formas de gobierno, propiedad y negocio de los otros microsistemas. Basta con pensar en las relaciones construidas con Google, pues Wikipedia se ubica siempre y sospechosamente en los primeros lugares en el motor de búsqueda:

La confiabilidad de Google como motor de búsqueda obtiene grandes réditos de que se la asocie al contenido neutral e imparcial de Wikipedia, lo que mejora su imagen como motor de búsqueda. Mutatis mutandis, Wikipedia se beneficia de un considerable aumento en el volumen de tráfico. (pp. 246-247)

Si bien la valoración de Van Dijck no es catastrofista, es decir, no ve en los medios conectivos un mal para las relaciones sociales, muestras de enajenación, simulacros, etc., no deja de ser evidente que su crítica se concentra exclusivamente en las relaciones entre los usuarios y los propietarios y cómo estos sacan provecho económico de los movimientos de aquellos en la red. Los datos presentados y el modelo de análisis construido para este caso resultan encomiables por el juicio para tratar un fenómeno que está en construcción y constante cambio. No obstante, su interés por las desiguales relaciones de poder entre usuarios y propietarios no le permite explorar otras formas de intercambio que se alejan, de hecho, de tales relaciones: formas de asociación entre iguales que permiten articular no solo intereses afectivos (gustos, tendencias, etc.), sino también intereses políticos: de género, sexuales, étnicos, de consumo, entre muchos otros, que evidencian que el ecosistema deja intersticios que permiten escenificar distintas formas de crítica, no circunscrita exclusivamente a la defensa de la privacidad o la circulación libre de contenidos, pues al margen de los contenidos aparecen acciones que no se pueden minimizar y que, de hecho, evidencian que estos medios no son solo conectivos sino también, y en gran medida, sociales. 